\title{
CRITERIA AND INDICATORS NEEDED TO ATTRACT SPONSORS AND DONATORS FOR SPORT
}

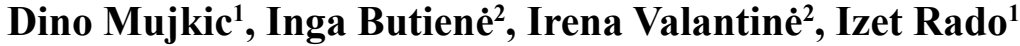 \\ University of Sarajevol, Sarajevo, Bosnia and Herzegovina \\ Lithuanian Sports University², Kaunas, Lithuania
}

\begin{abstract}
Background. Since 1980s, sponsorship has increasingly grown and is a powerful and strategic tool used by companies to support their marketing communication plans (Desbordes \& Tribou, 2007). Sports and culture sponsorships have become a popular and expensive marketing and public relations instruments. Very often it is clear that return on investment (ROI) is not an appropriate measure due to a lack of indicators established for this purpose. At the same time it is not clear what to follow and which criteria organizations should meet to get sponsorship or donation. The main aim of the research was to find the indicative markers to attract partners to participate in the sport and culture projects in accordance with well-established criteria for company promotion. Furthermore, exploring possibilities we aimed at developing common guidelines for sport, culture and educational institutions in order to have relevant common approach for company's partnership and to clarify it as a product's promotion and marketing sales of a company as social responsibility and excellent public relation.

Methods. The purpose of the study was to identify the objectives of sponsors we deem important when evaluating professional sport sponsorship opportunities in Bosnia and Herzegovina (BiH). Twenty-four valid responses, out of 30 received organizations that had sponsored sport and culture projects, were analysed to identify relevant criteria and indicators. The survey questions were designed based on the methods employed by other sponsorship researchers (Greenhalgh \& Greenwell, 2013).

Results and Conclusions. The present research was based on the information from questionnaires intentionally designed for targeting marketing or public relations managers in 24 organisations in BiH. Data processing, which included significance of differences and observed frequency distribution, along with ranking sponsorship objectives, criteria and indicators were used for conclusion, giving us a clear indicators' frame. The study results show that no transparent sponsorship or partnership criteria in line with organisation mission exist. It is more difficult for an organization or a project to identify and attract sponsors or partners. Measuring social responsibility as a tool for appropriate public relations strategy is one of the added values of the research.
\end{abstract}

Keywords: sponsorship, public relations, sport.

\section{INTRODUCTION}

$\mathrm{B}$ osnia and Herzegovina, unlike other former socialist countries in the region, had an established system of funding sport and culture based on clearly defined criteria. Stateowned companies invested a set percentage of their profit directly into sport and culture as a form of their social responsibility. This socialist system certainly had its downfall, but the criteria were clear. Towards the end of the eighties, with the beginning of privatization, this funding system was abolished and financing of sport and culture became based on voluntary actions and initiatives of individuals and groups that somehow managed to provide funds to carry out sport and cultural activities and events. This lack of adequate funding for sport and culture is the main reason why sponsor or donor organisations are seen as main funders of activities in Bosnia and Herzegovina. As the society is in a 
great demand for all sorts of fundamental activities that fall into this domain and make up one of its pillars, the companies are under great pressure with numerous demands for financing sport and cultural activities.

Past sponsorship research has focused on a great deal of attention on the effectiveness of sport sponsorships using measures such as sponsor recognition, intent to purchase from sponsors of sporting events, and the perceived benefits of sponsorship (Bennett, Cunningham, \& Dees, 2006; Eagleman \& Krohn, 2012; Maxwell \& Lough, 2009; Pitts \& Slattery, 2004). This paper is focused on the funding criteria and standards that the organisations use to determine which sport activities to support. Donations or sponsorships are one of the elementary methods in which projects in the field of sport and culture are financed, but also an instrument for the promotion of the companies' tangible and intangible values.

The results of this research are applicable to both culture and sport, as both fields are funded in the same way in Bosnia and Herzegovina. This paper offers a survey of the practice used so far and experiences based on the organisation's ROI, as well as guidelines to set the criteria for funding sports at the same time monitoring promotion of tangible and intangible values. The identification of objectives and a survey of the funding potentials was the basis for the initial research in this field in Bosnia and Herzegovina.

Sponsorship and marketing - What is tangible or intangible? Social responsibility or sales market? In the field of marketing, exchange denotes a transfer of something tangible or intangible or symbolic between groups or individuals - buyers and sellers. It, in fact, is an exchange or provision of transfer of something valuable - goods, services or ideas, for something that represents value - cash, credit or labour.

Although, marketing originally had to do with for-profit organizations, in the past several years it has spread to other fields of activities. With this in mind, it is well-known that sports organizations can find it difficult to provide finances for their activities, which poses difficulties in their organization. Therefore, social marketing plays a role in strengthening the links between businesses and society, and points to more effective ways of meeting social objectives and more efficient use of limited funds (Malacko \& Rađo, 2005).

Sports sponsorship is based on commercial, mutually valuable exchange, both in economic and social values and mutual relationship raising sense (Dilys \& Gargasas, 2014; Virvilaite \& Dilys, 2015). The objectives of a sponsorship program can incorporate elements of marketing, communications, relationship marketing, resource allocation, and networking. Despite claims of developments in management practice, the findings nevertheless show a widespread failure to pursue such objectives (Chadwick \& Thwaites, 2008). The responsibility for sponsorship or donation belongs to all stakeholders, sports organizations, organizations and companies, as well as the risk. The paper by Crompton (2014) focuses on the risks involving reputation and emphasizes that “...sponsorships relationship has to be fair to both sides. There will be an understanding that in exchange for their investment, companies need to secure a return on their investment. However, the company's sponsorship will be perceived to have both extrinsic motives (commercial considerations) and intrinsic motives (loyalty, support, belief in the property)" (p. 5). The research by Ko, Chang, Park, $\&$ Herbst (2016) points to the need for the managers to cooperate closely with sponsors on establishing an efficient strategy to contribute to the maximum benefit to both parties. Sponsorship has become well known through high-profile activities where companies spend millions associating themselves with events that attract massive media coverage. But in its early days, it also included support through patronage of less well-known projects. In the $21^{\text {st }}$ century, when businesses need to gain a return for their investment, can the support of grassroots events through sponsorship give them value for money? (Day, 2010). The way of financing is directed towards two forms of expected return on investment. One is the sponsorship-marketing based approach, i.e. selling of products and services, while the other focuses on the participation of the company as socially-responsible in upgrading and promoting essential, fundamental space for the development of sport and culture (grass-root).

The grass-root financing in Bosnia and Herzegovina is based on small-scale initiatives through grants offered by different levels of government. Due to the complex system and inexistence of standards and criteria, sports and culture suffer from insufficient funding. In this case, sports and culture organizations constantly initiate partnerships with companies in order to maintain their level of activities. These efforts often face inexistence of clear guidelines and criteria that 
should be observed in discussions, negotiations and even signing contracts with companies.

Besides the research into the approval criteria, this research is aimed at the capacities for changes that would successfully promote the need for a clear investment monitoring system. Researchers are currently focused on schedule and strategic approach to sponsoring of sports and culture and monitoring ROI. Jacobs, Pallav, Jain, and Surana (2014) point out that "one-third to one-half of US companies does not have a system in place to measure sponsorship ROI comprehensively." Based on these observations, they feel that "to manage sponsorship spending effectively, advertisers must first articulate a clear sponsorship strategy the overall objective of their portfolio, the target demographic, and which stages of the consumer decision journey (awareness, consideration, purchase, loyalty) sponsorships can support." In their paper Jensen and Cobbs (2014) emphasize the traditional marketing strategy measurable by number of publications and print as instruments to measure availability to users, as well as nontraditional marketing where instruments to measure sponsorship influence are scarce or inexistent.

There is a case for saying that, in these current political and financial times, all companies doing sponsorship should consider having a grassroots element to their overall programme; however, being commercial, companies need to ensure that they get value for money from their support, rather than just being philanthropic. Increasingly though, measurement of return on investment (ROI) is not just about the size of the media audience or the recent increase in sales, but can also be about other objectives such as customer awareness and loyalty, employee endorsement or government relations (Day, 2010).

Even though professional niche sport may exhibit a great need for sponsorship funding, they are in direct completion with mainstream professional sport properties, collegiate athletic departments, art, music, and entertainment events, and even charitable causes for finite amount of available corporate sponsorship support (Greenhalgh \& Greenwell, 2013). Sport sponsorship very often depends on relation between team loyalty, sponsorships awareness and attitude towards (Biscaia, Correia, Rosado, Ross, \& Maroco, 2013). Sales market also defines users and relationship of users towards sponsorship. In their research, in the part that gives recommendation for future research,
Koronios, Psiloutsikou, Kriemadis, and Kolovos (2016) reached the conclusion that companies are spending increasingly large sums of money sponsoring sport clubs without fully understanding what they are paying for in brand image building terms.

In their work, Walraven, Koning, Bijmolt, and Los (2016) used Data Envelopment Analysis (DEA) and gave recommendations for future research into different forms of sponsorships. Many sponsors pursue a multiple sponsorship strategy with several projects as part of a portfolio. Sometimes sponsored properties fall in the same sports category, whereas sometimes projects in other sports or even other sectors (such as culture) are sponsored.

\section{METHOD}

The survey questions were designed based on the methods employed by previous sponsorship researchers (Greenhalgh \& Greenwell, 2013). The organizations included in the research are those that participated in different forms of sponsorships. The contact points were the highest positioned managers, marketing managers or CEOs. The available emails were used to contact over 70 companies. However, which is unfortunately another indicator of the lack of interest and insufficient communications of marketing managers and managers, only 30 contacted organisations responded, out of which only 24 were considered valid, and could be used as a research sample. The questionnaires consisted of ordinary questions packed into the Google survey format.

The questionnaire had two parts, the first part was an open form with general information, mission, vision and values of the organisation, while the other closed part was related to the increase of sales/market share, raising awareness of the target market, raising awareness of the improved reputation of the company, involvement in the community, blocking/disabling competition, building trading links, social responsibility, changed public perception, improved relations among the staff, involvement in the corporate philanthropy, personal links to events or projects, national brand promotion, international brand promotion, personal promotion. Data processing, which included significance of differences and observed frequency distribution, along with ranking sponsorship objectives, criteria and indicators were used for conclusion, giving us a clear indicators frame. 


\section{RESULTS}

Out of the total of 30 companies that responded to the questionnaire, 24 were valid for data processing. Statistically significant differences of the observed frequencies where assessed using $\mathrm{Hi}$ squared test $\left(\chi^{2)}\right.$ applying the model of "all groups equal". Companies were highly developed in business area including one company in banking and investment, two IT, one in food production, 2 in media and 16 companies marking "Other" as an answer.

Twenty-two companies have clearly defined mission and vision $\left(\chi^{2}=16.67 ; p<.001\right)$, twenty companies have defined company values, marketing plans and marketing plans made according to the company mission $\left(\chi^{2}=10.67 ; p<\right.$ $.001)$ while seventeen do not make public call for sponsorship $\left(\chi^{2}=4.17 ; p=.041\right)$. Specific research results showed inconsistency with no significant differences for sponsorship criteria and evaluation of the sponsored projects $\left(\chi^{2}=0.167 ; p=.68\right)$. Not a single company chose social development or social responsibility as their values. The missions do not contain the key words related to sports or culture.
Not a single company responded that they followed specific indicators.

Indicators and criteria of sponsorship were graded using Likert scale where 1 means least important through 5 as very important (Table). Significant differences were observed when it comes to "Increased market share" where $41.7 \%$ were marked as highly important $\left(\chi^{2}=11.74 ; p=\right.$ $.02)$, "Raised awareness on the target market" (grade $5-45.5 \% ; \chi^{2}=16.83 ; p=.002$ ), "Improved company reputation" (grade $5-58.3 \% ; \chi^{2}=10.75$; $p=.005$ ), "Improved relations among staff" (grade $\left.4-48.8 \%, \chi^{2}=12.25 ; p=.016\right)$, "Involvement in Corporate Philanthropy" (grade 3-37.\%, grade $\left.433.3 \% ; \chi^{2}=10.17 ; p=.038\right)$, "Personal bond with event" (grade $3-41.7 \% ; \chi^{2}=9.75 ; p=.045$ ) and "National brand promotion" (grade 5-45.8\%; $\chi^{2}=$ 19.33; $p=.001)$, respectively.

\section{DISCUSSION AND CONCLUSION}

Besides the fact that twenty-two companies have clearly defined mission and vision, twenty companies have defined company values, marketing plans and marketing plans made according to

Table. Analysis of criteria and indicators of sponsorship

\begin{tabular}{|l|c|c|c|c|c|c|c|c|c|}
\hline & $\mathbf{1}$ & $\mathbf{2}$ & $\mathbf{3}$ & $\mathbf{4}$ & $\mathbf{5}$ & Mean & Median & $\chi^{2}$ & $\boldsymbol{p}$ \\
\hline Increased market share & 8.3 & 4.2 & 29.2 & 16.7 & 41.7 & 3.79 & 4 & 11.42 & $\mathbf{. 0 2}$ \\
\hline $\begin{array}{l}\text { Raised awareness on the target } \\
\text { market }\end{array}$ & 4.2 & 4.2 & 12.5 & 33.3 & 45.8 & 4.12 & 4 & 16.83 & $\mathbf{. 0 0 2} * *$ \\
\hline Raised public awareness & 8.3 & 0 & 33.3 & 33.3 & 25 & 3.67 & 4 & 4.0 & .26 \\
\hline Improved company reputation & 0 & 0 & 4.2 & 37.5 & 58.3 & 4.5 & 5 & 10.75 & $\mathbf{. 0 0 5} * *$ \\
\hline Participation in the community & 0 & 0 & 16.7 & 37.5 & 45.8 & 4.29 & 4 & 3.25 & .197 \\
\hline Blocked/disabled competition & 25 & 29.2 & 25 & 20.8 & 0 & 2.41 & 2 & 0.33 & .954 \\
\hline Building trade links & 8.3 & 12.5 & 29.2 & 37.5 & 12.5 & 3.33 & 3.5 & 7.67 & .105 \\
\hline $\begin{array}{l}\text { Participation in social } \\
\text { responsibility }\end{array}$ & 8.3 & 0 & 16.7 & 41.7 & 33.3 & 3.91 & 4 & 6.67 & .083 \\
\hline Change of public perception & 0 & 0 & 29.2 & 41.7 & 29.2 & 4 & 4 & 0.75 & .69 \\
\hline Improved relations among staff & 8.3 & 8.3 & 12.5 & 45.8 & 25 & 3.7 & 4 & 12.25 & $\mathbf{. 0 1 6 *}$ \\
\hline $\begin{array}{l}\text { Corporate philanthropy } \\
\text { involvement }\end{array}$ & 4.2 & 12.5 & 37.5 & 33.3 & 12.5 & 3.37 & 3 & 10.17 & $.038^{*}$ \\
\hline Personal bonds with the event & 16.7 & 4.2 & 41.7 & 25 & 12.5 & 3.13 & 3 & 9.75 & $\mathbf{. 0 4 5 *}$ \\
\hline National brand promotion & 4.2 & 4.2 & 8.3 & 37.5 & 45.8 & 4.16 & 4 & 19.33 & $\mathbf{. 0 0 1 * *}$ \\
\hline International brand promotion & 20.8 & 8.3 & 8.3 & 29.2 & 33.3 & 3.45 & 4 & 6.42 & .17 \\
\hline Personal promotion & 41.7 & 8.3 & 12.5 & 20.8 & 16.7 & 2.63 & 2.5 & 8.08 & .089 \\
\hline
\end{tabular}

Note. $* *$ - significant at $99 \%, *$ - significant at $95 \%$. 
the company mission, not a single respondent defined their values towards achieving additional intangible values, i.e. social responsibility. In essence, sponsorship or donations are observed as a social responsibility concept, but there are no measuring instruments or indicators that point to the implementation of the set objectives. Besides the intangible values, it is expected that the companies turn their sponsorship goals towards several marketing directions. The objectives of a sponsorship program can incorporate elements of marketing communications, relationship marketing, resource allocation, and networking (Chadwick \& Thwaites, 2005). Tangible values are not clearly defined by criteria and indicatory; therefore it is clear that there are no sponsorship programs. We assume that there is no clear link between the projects funded and the company indicators, and that the ROI was not calculated adequately. Earlier research of this type in places with higher capacities for systematic planning of investments and return of the invested funds through sponsorship programs show that the companies have space for improvement. The research by Chadwick \& Thwaites (2005) concludes that the sponsorship of English professional football clubs continues to be very popular among corporations. As such, the medium's overall appeal is not in question, although this article justifies the need for more professional management of the activity. Moreover, the study confirms the need for corporations to think differently about sponsorship; unlike other forms of marketing communication, sponsorship has the potential to fulfil a much greater and more powerful strategic network, and relationship marketing role. This is, nevertheless, dependent upon changes in the nature of power and the cultural foundations within and between the organizations involved in the soccer sponsorship dyad.

In Bosnia and Herzegovina, keeping in mind the sports and culture funding system, and the inadequate awareness on intangible values earned from financing sports and cultural events, there is a dire need to find new models that would benefit both sports and cultural organizations, and the companies with increased interest into co-financing such activities. The new professionalism and setting up the elementary criteria and measurable monitoring indicators is the task for all stakeholders. If sports organizations have clear criteria based on which the companies want to become partners, it is easier to establish interest that guarantees achieving both tangible and intangible values.

Limitations and Directions for Future Research. This study is the first such type study in Bosnia and Herzegovina. We would even consider it as the pilot study, as the way in which we managed to collect data speaks of the lack of awareness on the need for synergy between companies and sports organizations on planning sponsorship programs and determining shared criteria and success indicators. The next research will include clearly defined criteria and model for monitoring ROI, which will probably make it more acceptable for the future cooperation between companies and sports organizations. The database with the responses from companies we got in the direct contact indicates that even those managers that are in charge of marketing or PR do not recognize the potential of the synergy on the market, but often respond to initiatives negatively out of insufficient interest or knowledge. Clear criteria would provide better communication that is currently often based on personal links that a manager has with a sports organization.

We feel that we were limited by the interest of the companies, but at the same time we feel that there is a possibility to introduce our intentions to the managers, thus creating grounds for better cooperation. Raising awareness on the synergy and joint action is one of the main tasks for the future research, aimed at overcoming these limitations. We strongly believe that the need to create initial criteria opens doors for the continuation of this research with clearly set proposals and examples.

\section{REFERENCES}

Bennett, G., Cunningham, G., \& Dees, W. (2006). Measuring the marketing communication activations of a professional tennis tournament. Sport Marketing Quarterly, 15, 91-101.

Biscaia, R., Correia, A., Rosado, A. F., Ross, S. D., \& Maroco, J. (2013). Sport sponsorship: The relationship between team loyalty, sponsorship awareness, attitude toward the sponsor, and purchase intentions. Journal of Sport Management, 27(4), 288-302.

Chadwick, S., \& Thwaites, D. (2008). Commitment in sponsorship relationships. Journal of General Management, 34, 71-90. 
Chadwick, S. \& Thwaites, D. (2005). Managing sport sponsorship programs: Lessons from a critical assessment of English soccer, Journal of Advertising Research, 45(3), 328-338. doi: 10.1017/S0021849905050312.

Crompton, J. L. (2014). Potential negative outcomes from sponsorship for a sport property. Managing Leisure, 19(6), 420-441. doi: 10.1080/13606719.2014.912050

Day, H. (2010). The value of grassroots sponsorship. Journal of Sponsorship, 3(3), 209-212.

Desbordes, M., \& Tribou, G. (2007). Sponsorship, endorsements and naming rights. In J. Beech \& S. Chadwick (Eds.), The marketing of sport (pp. 267291). London: Pearson Education.

Dilys, M., \& Gargasas, A. (2014). Structural business model based on cooperation between sports organizations and sponsors. Engineering Economics, 25(1), 94-102. doi: http://dx.doi.org/10.5755/j01.ee.25.1.2680.

Eagleman, A. N., \& Krohn, B. D. (2012). Sponsorship awareness, attitudes, and purchase intentions of road race series participants. Sport Marketing Quarterly, 21, 210-220.

Greenhalgh, G., \& Greenwell, T. C. (2013). What's in it for me? An investigation of North American professional niche sport sponsorship objectives. Sport Marketing Quarterly, 22(2), 101-112.

Jacobs, J., Pallav Jain, P., \& Surana, K. (2014). Is sports sponsorship worth it? McKinsey \& Company. Retrieved from http:/www.mckinsey.com/business-functions/ marketing-and-sales/our-insights/is-sports-sponsorshipworth-it.
Jensen, J. A., \& Cobbs, J. B. (2014). Predicting return on investment in sport sponsorship. Journal of Advertising Research, 54(4), 435-447. doi: 10.2501/JAR-54-4-435-447

Koronios, K., Psiloutsikou, M., Kriemadis, A., \& Kolovos, P. (2016). The effect of perceived motivation of sports sponsorship: Evidence from basketball fans. International Journal of Business \& Economic Sciences Applied Research, 9(2), 33-45.

Ko, Y. J., Chang, Y., Park, C., \& Herbst, F. (2016). Determinants of consumer attitude toward corporate sponsors: A comparison between a profit and nonprofit sport event sponsorship. Journal of Consumer Behaviour, 16(2), 176-186. doi: 10.1002/cb.1622

Malacko, J. \& Rađo, I. (2005). Technology for sports and sports training. [Tehnologija sporta i sportskog treninga in Bosnian]. University book, Faculty of Sport and Physical education, Sarajevo.

Maxwell, H., \& Lough, N. (2009). Signage vs. no signage: An analysis of sponsorship recognition in women's college basketball. Sport Marketing Quarterly, 18, 188-198.

Pitts, B. G., \& Slattery, J. (2004). An examination of the effects of time on sponsorship awareness levels. Sport Marketing Quarterly, 13, 43-54.

Virvilaite, R., \& Dilys, M. (2015). Formatting sport organization image as a competitive advantage trying to attract more sponsors. Engineering Economics, 21(5), 561-567.

Walraven, M., Koning, R. H., Bijmolt, T. A., \& Los, B. (2016). Benchmarking sports sponsorship performance: Efficiency assessment with data envelopment analysis. Journal of Sport Management, 30(4), 411-426. doi: 10.1123/jsm.2015-0117.
Corresponding author Irena Valantine

Department of Sport Management, Economics and Sociology Lithuanian Sports University

Sporto str. 6, LT-44221, Kaunas

Lithuania

Tel. + 37037203489

E-mail irena.valantine@1su.lt 